\title{
A quinta estação de Jorge de Sena
}

\author{
The fifth season of Jorge de Sena
}

Francisco Ferreira de Lima ${ }^{1}$

Resumo: Fundamentado na leitura de alguns poetas do século XVI, que exploraram o topos da mudança, através do qual se constata a irreversível assimetria entre os ciclos da natureza e os da vida humana, o texto apresenta uma breve leitura do poema «As quatro estações eram cinco» de Jorge de Sena. A meta é, simultaneamente, marcar proximidades e enfatizar diferenças de concepção de tempo entre o poeta do século XX e a de seus antecessores.

Palavras-Chaves: Jorge de Sena; tempo; poesia do século XX; poesia do século XVI.

\begin{abstract}
Based on the reading of some poets of the $16^{\text {th }}$ century, which explored the topos of changing, through which one gets the irreversible asymmetry between the cycles of nature and of human life, the text presents a brief approach of the poem «As quatro estações eram cinco» by Jorge de Sena. The goal is both to highlight affinities and emphasize differences in depicting time between the $20^{\text {th }}$ century poet and his predecessors.
\end{abstract}

Keywords: Jorge de Sena; time; $20^{\text {th }}$ century poetry; $16^{\text {th }}$ century poetry.

\footnotetext{
${ }^{1}$ Universidade Estadual de Feira de Santana. Professor Titular aposentado na Universidade Estadual de Feira de Santana, é mestre e doutor em Literatura Portuguesa. Tem vários artigos e livros publicados. 0 último deles é $O$ real e o avesso: O mar em Camões e Pessoa \& outros temas, editado em 2018, em Salvador, pela Rio do Engenho.
} 
As quatro estações eram cinco

O verão passa e o estio se anuncia

que o outono se há de ser e logo inverno

de que virá nascida a primavera.

Mais breve ou longo se renova o dia

sempre da noite em repetir-se, eterno.

Só o homem morre de não ser quem era.

08/01/1970

(Sena, 2013: 573)

Sempre que leio ou penso em Jorge de Sena vem-me à mente a imagem de poeta estabelecida por Camões, moldada em quatro versos lapidares em Os Lusíadas: «Nem me falta na vida honesto estudo, / Com longa experiência misturado. / Nem engenho, que aqui vereis presente, / cousas que juntas se acham raramente» (X,154). É bem possível que o poeta estivesse falando dele mesmo, mas acaba por definir um modo de ser (poeta) e um modo de estar no mundo, lendo-o e interferindo nele, (quase) arrogante na certeza e consciência de sua grandeza - pouco, pouquíssimo reconhecida em seu tempo, aliás.

Tal como no caso daquele seu feliz e infeliz antecessor, esses versos parecem a mais perfeita tradução desse poeta do século XX, a quem também não faltavam honesto estudo, experiência, engenho e uma enorme consciência de sua grandeza, que, hoje, é quase um clichê repetir, o põem ao lado do próprio Camões e do outro gigante, Fernando Pessoa. Enquanto viveu, entretanto, teve negado esse reconhecimento - não se sabe se por sua genialidade muito além do seu tempo, se por seu desejo de ter essa grandeza reconhecida, desejo que muito frequentemente se travestia de agressividade, se pela pequenez ou má vontade dos seus contemporâneos, ou se por tudo isso junto.

O fato é que essa indiferença o fez duplamente exilado: do mundo real, fugindo sucessivamente de ditaduras em Portugal e no Brasil; e da república das letras, que, ante a ameaça explícita de seu talento combativo, o expulsou, como fazem as repúblicas com os poetas desde o filósofo grego. Nessa desafortunada condição, sem poder participar da vida social/política/literária de seu país, como se dá com o comum dos mortais, e estrangeiro no país dos outros, o poeta dedicou-se ao que cabia dedicar-se um poeta em duplo exílio: leu e escreveu como um condenado!

E tudo, do aspecto mais grandioso ao mais pequeno, tudo the interessava, como se tivesse se atribuído a tarefa de abarcar o mundo com as mãos - conta-se, talvez agora já um pouco entre a verdade e a lenda, que a pressa era tanta que não sobrava tempo sequer para rever textos, pois gostava de dizer que um poema revisto era um novo poema. Da questão política premente sua contemporânea até ao intricado argumento filosófico pré-socrático, nada escapou à sua máquina (e tome-se aqui essa palavra em sentido bem mais amplo que o objeto físico) de escrever. O resultado é uma obra - e uma vida! - que ainda está por ser 
devidamente compreendida na sua imensa complexidade e que cobre todas as modalidades do fazer literário, seja a poesia, o conto, o romance, o drama, o ensaio e a epistolografia, para ficarmos com as principais.

E se escreveu assim, leu na mesma ou em maior medida. Boa parte de sua obra é o que bem se poderia chamar de homenagem à literatura - para lembrar Fiama Hasse Paes Brandão. Trata-se de um diálogo permanente, reverente e respeitoso, com as formas e sentidos da tradição literária, desde os seus começos mais remotos. Tal prática o leva a um prazeroso exercício de poesia sobre a poesia, como se recuasse no tempo e decidisse emular os grandes, como se pedia e se fazia naqueles dias, simultaneamente homenageando-os e ampliando os horizontes de poesia e de vida.

É o que se pode ver no poema acima, escolhido para uma breve leitura.

Como se pode observar, o tema é recorrente na poesia, muito especialmente a renascentista. Trata-se da resignada constatação do descompasso entre os ciclos da natureza, que dão uma volta completa sobre si mesmos, e o ciclo da vida humana, único e irrepetível, que se estabelece como uma linha reta. $O$ tema foi exaustivamente tratado por muitos poetas do renascimento, que o transformaram num topos obrigatório da poesia de todos os tempos.

Ele re-surge com força, grosso modo, como efeito da descoberta da pequenez do humano ante a dimensão infinita do mundo, no qual Deus, ainda que onipresente, parecia estar bem mais distante do homem do que supunham os áureos tempos medievais. Essa distância e essa misteriosa grandiosidade do infinito autorizaram o homem a moldar aquilo que depois viria a se chamar, para ficarmos em termos gerais, «consciência de indivíduo», isto é, a tarefa de modelar sua subjetividade, tarefa essa que, como em todo ato de construção, implicou prazer e dor. Daí que ela tenha transitado da euforia de o homem redescobrir-se «a medida de todas as coisas» à disforia de saber-se relativamente só no mundo, tendo que nele construir seu lugar como sujeito, de modopor forma a atribuir sentido à sua vida e ao mundo, posto que já não lhe seriam dados de graça, como soía acontecer nos velhos e bons tempos em que se sentia e se vivia a certeza da proximidade da presença de Deus.

Dentre as dores recém-surgidas, ou recém-retomadas, a de a vida se desenvolver em linha reta em direção à velhice e à morte, em contraste com o eterno retorno da natureza, através do qual o velho é outra vez o novo, foi uma dor profunda.

Apenas para efeito de demonstração, marco a presença desse topos em apenas três grandes poetas daquela época. Mas poderia fazê-lo em dezenas de outros, que quase todos nele se detiveram. Ele já está bem definido, por exemplo, em Sá de Miranda, em um de seus sonetos mais célebres, que assim se fecha: 
«Tudo é seco e mudo; e, de mestura,/Também mudando-m'eu fiz doutras cores: / E tudo o mais renova, isto é sem cura!». Com pequena diferença, está em Camões: «O tempo cobre o chão de verde manto, / Que já coberto foi de neve fria, / $E$ em mim converte em choro o doce canto» (Torres, 1977, I: 947). E, por fim, algum tempo depois, pode ainda ser encontrado em Francisco Rodrigues Lobo, no seu magistral soneto sobre o Tejo: «Mas lá virá a fresca Primavera: / Tu tornarás a ser quem eras dantes, / Eu não sei se serei quem dantes era» (Torres, 1977, II: 42).

Ressalvados aspectos estéticos, observa-se a mesma resignada angústia quanto à inexorável viagem do homem rumo à velhice e à morte, como se a natureza o tivesse expulsado do seu seio, depois de fazê-lo confundir-se com ela - daí o «mudando-m’eu» de Sá de Miranda, o «doce canto» camoniano e o «quem dantes era» de Lobo, todos lamentando a terrível descoberta de terem sido, melhor, de terem vivido o que já não vivem; o que já não mais viverão.

A natureza, pelo contrário, impassível ao drama humano, como que festeja a união dos dois extremos - infância e velhice, nascimento e morte -, transformando-os tão-somente em partes de um processo, através do qual o que era novo envelhece e volta a ser novo; o que era nascimento morre e volta a nascer. Esse movimento funciona, portanto, como um espelho do impossível desejo humano de vencer a velhice e a morte. Desgarrado da natureza, o «eu» vê-se vítima inexorável daquele incorruptível «compositor de destinos», como o bem definiu Caetano Veloso.

É este o tema do poema de Jorge de Sena, na sua bela homenagem aos poetas que o antecederam: o homem e sua solitária viagem rumo à morte em face da natureza em seu eterno retorno. Falando dos três poetas citados, já se está, pois, falando também dele.

Vejamos, entretanto, o poema de perto. Profundo conhecedor do soneto quinhentista peninsular, hábil ele próprio na construção dessa forma, a primeira pergunta que se poderia pôr era o porquê de ele ter evitado desenvolver o tema num soneto ao modo clássico, como seria de esperar.

Não é difícil a resposta, creio eu. Poeta de outro tempo, Sena faz evidente no seu poema o multiplicar-se vertiginoso da passagem do tempo, aspecto que o soneto, em seu formato cerebral, não mais daria conta. O tempo é um nos sonetos dos seus antecessores e já é outro no tempo de Sena. Daí que o que cabia adequadamente em 14 versos, racionalmente distribuídos em 2 quartetos e 2 tercetos, agora só precise de 6 exíguos versos para dar-se a ler na sua inteireza. Em suma: o tempo é um no renascimento; outro no século Xx. Tudo se passa como se a própria substância do tempo sofresse uma alteração radical em termos de sua dinâmica interna. 
É, pois, não apenas o tempo que movimenta o poema de Sena, mas, antes, sua vertigem. E ela é rigorosamente desenhada no movimento dos três versos iniciais do poema, que, somados, cobrem metade de todo o texto! Observe-se que não há um único elemento de pontuação a criar qualquer barreira entre os três versos, o que obriga o leitor a percorrê-los com a mesma velocidade que eles anunciam. O tempo, diz-nos o poema, em sua voraz passagem, não reconhece pausa ou obstáculo. Nada há a impedir seu caminho! E assim, embora lá estejam detalhadas as estações, não se tem nenhuma delas em si, pois cada uma encadeia-se na seguinte numa espécie de mágica fusão entre o fim de uma e o começo da outra, fundindo-as todas num caudaloso rio do tempo. Caudal que se adensa na profusão de sibilantes distribuídas ao longo desses três versos (paSSa, eStio, Se anunCia, Se há-de Ser, NaSCida) e que obriga o leitor a experimentar fisicamente a velocidade da vertigem, revelada nesses sons de ventanias.

Os dois versos seguintes, o quarto e o quinto, tornam clara a ideia de repetição, de ciclo, que não se definira bem na primeira parte do poema, visto que ali se tratava de enfatizar o vertiginoso da passagem do tempo em sua literal contiguidade. Ali importava mais destacar a fusão do que o ciclo: o tempo é uma unidade, um fluxo contínuo, não obstante a ilusão que a aparência das estações oferece aos olhos.
Agora, nos quarto e quinto versos, apresentam-se, digamos assim, os elementos que compõem essa unidade, tal como se se estivesse a falar de uma unidade de medida. Ficamos a saber que é na relação noite/dia que tal unidade se organiza. Daí que não importe dia mais longo, dia mais curto, pois todos são filhos da noite, que, na escuridão de suas sombras, os faz brotar envoltos na dimensão mágica da eternidade, razão pela qual merecem essa vírgula antes de «eterno», cujo efeito é dotar a eternidade de uma espécie de autossuficiência que se basta a si mesma. Longos ou curtos, o que os marca é sua intrínseca eternidade. E, assim, avança-se da ideia de ciclo para a de eternidade como coisa em si.

Está, pois, criado o contexto perfeito para a introdução do homem nesse ambiente. E ele vem num verso magistral, num fecho de ouro ao modo clássico: «Só o homem morre de não ser quem era». Então se pode entender ainda melhor o papel daquele «eterno» isolado no verso anterior. Seu isolamento reforça a dimensão trágica da morte do homem em sua fugaz transitoriedade: o homem morre de não ser quem era. Isto é, não só do que supôs ser, mas do que efetivamente foi.

E o que já foi o homem? Um igual da natureza, responde o poema. Por um tempo, numa curta fase de sua vida, o homem vive efetivamente como parte da natureza. Assim como para a natureza, para a criança - retome-se o «doce canto» camoniano -, os dias mais 
longos ou curtos são eternidades renovadas no seio da noite. E ela os vive como tais, na sua dimensão de eternidade, como se toda criança fosse um Alberto Caeiro, ou o contrário, como se todo Alberto Caeiro fosse uma criança para quem «pensar é estar doente dos olhos». Como a natureza, como Caeiro, a criança não pensa; a criança vive.

E aí, finalmente, pode-se compreender o algo enigmático do título do poema: «As quatro estações eram cinco». De fato, e ainda que por pouco tempo - e nisso, a meu ver, o poema de Sena renova o topos -, se o homem vive efetivamente integrado na natureza, com ela con-fundido, ele é mais que um homem; mais que um igual da natureza. É natureza em estado puro. É, portanto, sua quinta estação. E assim, por um dia que seja, longo ou curto, não importa, as estações, em vez de quatro, são cinco na vida de todo ser humano.
Todavia, como não se pode ser criança o tempo todo e Alberto Caeiro é só um poeta de papel, e o pensamento a tudo inunda, a tudo contamina e a tudo corrói, a natureza, mais dia, menos dia, apresenta sua fatura: de natureza pura, o homem agora é um seu desigual. E o preço é a exclusão do círculo, que se traduz, primeiro em velhice - retome-se o velho Sá, «mudando-meu fiz doutras cores» - e depois em morte, sobre as quais, velhice e morte, a natureza, em seu perpétuo movimento de renovação, parece lançar, no máximo, um trivial e fugaz olhar de indiferença.

\section{Bibliografia}

Camões, L.V. de. (1978). Os Lusíadas. Figueirinhas. Porto;

Camões, L.V. de. (1980). Lírica completa. (Pref. e notas de Maria de Lurdes Saraiva). INCM. Lisboa.

Sena,J. de. (2013). Poesia 1: Obras Completas de Jorge de Sena. Guimarães. Lisboa;

Torres, A.P. (1977). Antologia da poesia portuguesa. Lello \& Irmão. Porto. 